\section{Colonic schistosomiasis and early rectal cancer: coincidence or causal relationship?}

A 74-year-old woman was referred for endoscopic resection of a laterally spreading rectal tumor of the nongranular pseudodepressed subtype ( Fig.1 a). The 25-mm lesion had been diagnosed during screening colonoscopy and the patient denied any symptoms. Resection was performed en bloc by endoscopic submucosal dissection (ESD). Histology showed pT1 carcinoma with a submucosal depth of invasion of $200 \mu \mathrm{m}$ ( $\bullet$ Fig. 1 b). Close to the laterally spreading rectal tumor, a submucosal yellowish lesion $3 \mathrm{~mm}$ in diameter was seen ( $\bullet$ Fig. 2 a). A neuroendocrine tumor was suspected macroscopically and ESD was performed. Surprisingly, histopathological examination of the specimen revealed granuloma with calcification containing schistosomal ova ( $\bullet$ Fig. 2 b). The patient recalled a diagnosis of schistosomiasis 27 years earlier when she had travelled to Uganda. Treatment had been performed with praziquantel immediately after diagnosis and her further course was uneventful.

Schistosomiasis is frequent in African and Asian regions. Asian authors have reported on colonic involvement such as acute colitis during the early period of the disease but also as chronic changes years after the infection (mucosal atrophy, submucosal fibrosis, polyps, submucosal nodules, persistence of schistosomal ova) [1 - 3]. Because of the geographic distribution of the disease, colonic changes as a result of schistosomiasis are generally unknown to Western endoscopists and reports from the Western world are rare [4]. Similar to the relationship between schistosomiasis and bladder cancer, Asian and African reports have proposed a causal relationship between chronic inflammatory changes of the colonic mucosa and colorectal carcinogenesis [2,5]. Some authors recommend surveillance colonoscopy after colonic schistosomiasis, even after successful treatment [5]. In the light of increasing globalization and migration, Western endoscopists should be aware of colonic schistosomiasis, its discrete endoscopic findings, and its potential role in colorectal carcinogenesis.
Endoscopy_UCTN_Code_CCL_1AC_2AG

Competing interests: None

\section{Andreas Probst ${ }^{1}$, Tina Schaller ${ }^{2}$, Alanna Ebigbo" ${ }^{1}$ Helmut Messmann'}

1 Department of Gastroenterology, Klinikum Augsburg, Augsburg, Germany ${ }^{2}$ Institute of Pathology, Klinikum Augsburg, Augsburg, Germany

\section{References}

1 Cao J, Liu WJ, Xu XY et al. Endoscopic findings and clinicopathologic characteristics of colonic schistosomiasis: A report of 46 cases. World J Gastroenterol 2010; 16: 723-727

2 Liu W, Zeng HZ, Wang QM et al. Schistosomiasis combined with colorectal carcinoma diagnosed based on endoscopic findings and clinicopathological characteristics: A report on 32 cases. Asian Pac J Cancer Prev 2013; $14:$ : 4839-4842

3 Zhou YQ Huo JR, Liu DL et al. Colonic schistosomiasis mimicking submucosal tumor. Endoscopy 2011; 43 (Suppl. 02): E58-E59

4 Gray DM 2nd, Nakashima M, Davidson NO. Education and imaging. Gastrointestinal: schistosomiasis - diagnosis by colonoscopy. J Gastroenterol Hepatol 2013; 28: 763

5 Konishi T, Watanabe T, Shibahara J et al. Surveillance colonoscopy should be conducted in patients with colorectal Schistosomiasis even after successful treatment of the disease. Int J Immunopathol Pharmacol 2006; 19: $245-246$

\section{Bibliography}

DOI http://dx.doi.org/

10.1055/s-0034-1390863

Endoscopy 2014; 46: E671

(C) Georg Thieme Verlag KC

Stuttgart · New York

ISSN 0013-726X

\section{Corresponding author}

\section{Andreas Probst, MD}

III. Medizinische Klinik

Klinikum Augsburg

Stenglinstrasse 2

86156 Augsburg

Germany

Fax: +49-821-4003331

andreas.probst@klinikum-augsburg.de
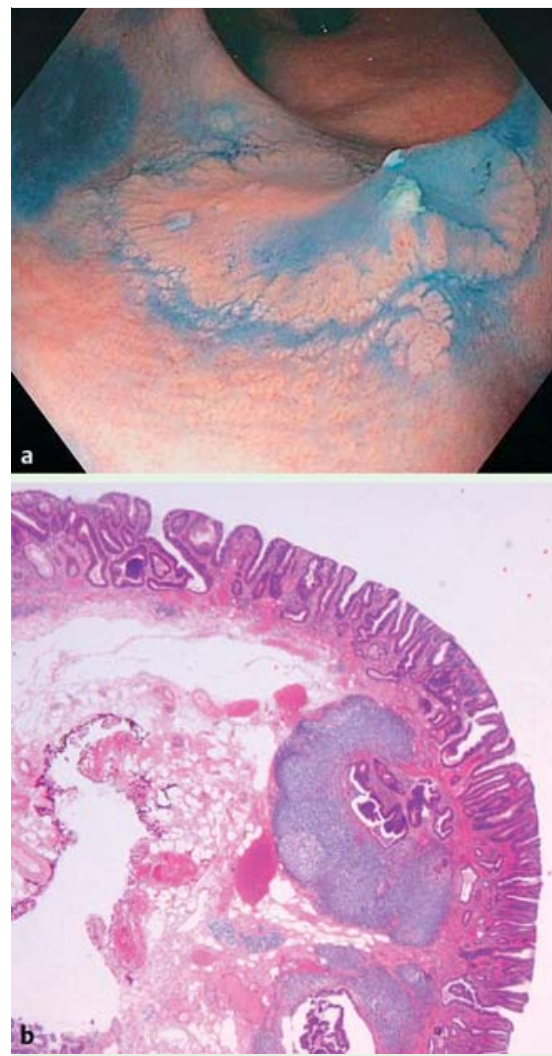

Fig. 1 a Laterally spreading rectal tumor of the nongranular pseudodepressed type in a 74-year-old woman; chromoendoscopy with indigo carmine. b Resection specimen showing focal carcinoma with submucosal invasion of $200 \mu \mathrm{m}$.

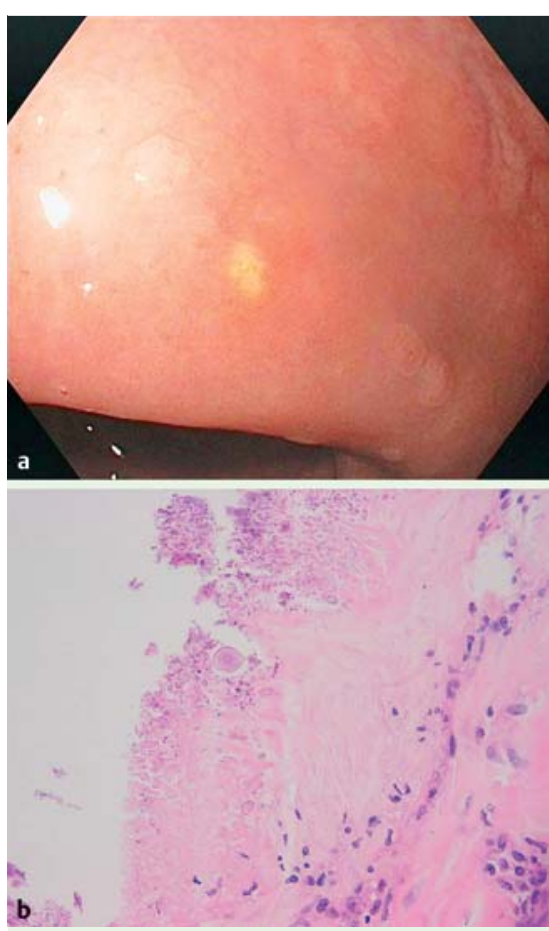

Fig. 2 a Submucosal yellowish nodule $3 \mathrm{~mm}$ in diameter in the proximal rectum. $\mathbf{b}$ Resection specimen showing granuloma with calcification containing schistosomal ova. 